\title{
Predictors of unfavourable tuberculosis treatment outcome in Bilene District, Gaza Province, Mozambique: A retrospective analysis, 2016 - 2019
}

\author{
D Osório, ${ }^{1, *} \mathrm{MD}$ (D); I Munyangaju, ${ }^{2, *} \mathrm{MD}, \mathrm{MSc}$; E Nacarapa, ${ }^{2,3, *} \mathrm{MD}, \mathrm{MSc} ; \mathrm{A}-\mathrm{V}$ Nhangave, ${ }^{4} \mathrm{BSc} ; \mathrm{J}-\mathrm{M}$ Ramos-Rincon, ${ }^{5} \mathrm{MD}, \mathrm{PhD}$ \\ ${ }^{1}$ General Medicine/Paediatrics Department, Centro de Saúde de Macia, Gaza, Mozambique \\ 2 Tinpswalo Association - Vincentian Association to Fight AIDS and TB, Gaza, Mozambique \\ ${ }^{3}$ Internal Medicine Department, Carmelo Hospital, Gaza, Mozambique \\ ${ }^{4}$ Gaza Provincial Research Nucleus, Provincial Health Directorate, Mozambique \\ ${ }^{5}$ Internal Medicine Department, General University Hospital of Alicante and University Miguel Hernandez de Elche, Alicante, Spain \\ * These authors contributed equally to this work
}

Corresponding author: I Munyangaju (imunyangaju@gmail.com)

Background. Tuberculosis (TB) is a serious public health problem and remains one of the leading causes of death from an infectious agent globally. Mozambique is one of 30 countries considered to have a high TB burden.

Objectives. To describe the clinical characteristics of TB in children and adults in Bilene District in Gaza Province, Mozambique, over 43 months and to assess determinants of unfavourable treatment outcomes.

Methods. This retrospective cohort study took place from 1 January 2016 to 31 July 2019 in Bilene District, Gaza. We included patients in the TB register at the Centro de Saúde de Macia TB unit with available data on final treatment outcome. Predictors of unfavourable outcomes were determined using multivariable logistic regression models.

Results. A total of 3012 TB-infected patients were registered in the TB unit of the Macia health facility during the study period: 358 (11.9\%) were children (<14 years), $1522(50.5 \%)$ were male, and 2581 (85.7\%) were new TB cases. No bacteriological test was performed at diagnosis in 1250 patients (41.5\%). Treatment was successful in 2863 patients (95.1\%), with better outcomes in children than in adults ( $98.0 \%$ v. $94.6 \% ; p=0.005)$. Although mortality $(n=97 ; 3.2 \%$ ) was low in both groups, the proportion who died was lower in children compared with adults $(1.4 \%$ v. $3.5 \%$; $p=0.035)$. Multivariable logistic regression analysis showed that unfavourable outcomes were more likely in men compared with women (adjusted odds ratio (aOR) 1.48; 95\% confidence interval (CI) $1.04-2.12$; $p=0.029$ ), in patients with recurrent TB infection compared with newly infected patients ( $\mathrm{aOR} 1.63 ; 95 \% \mathrm{CI} 1.05-2.50 ; p=0.027$ ), and in patients co-infected with TB and HIV compared with HIV-negative TB-infected patients (aOR 2.17; 95\% CI 1.43 - 3.29; $p<0.001$ ). The factor conferring the most risk for an unfavourable outcome was positive microbiological sputum results (aOR 5.27; 95\% CI $3.25-8.54$; $p<0.001$ ).

Conclusions. Factors independently associated with an unfavourable TB treatment outcome were male sex, recurrent TB infection, having positive microbiology, and co-infection with HIV. It remains crucial to improve data quality and adherence to TB screening and diagnostic algorithms.

S Afr Med J 2022;112(3):234-239. https://doi.org/10.7196/SAMJ.2022.v112i3.16193

Tuberculosis (TB) is a serious public health problem and remains one of the leading causes of death from an infectious agent globally. However, it is preventable and curable. Treatment consists of a combination of antituberculosis drugs, taken for $6-20$ months depending on the location of disease and the presence of drug resistance. There are also several equally effective regimens for preventing $\mathrm{TB}$, with durations ranging from 1 to 6 months. ${ }^{[1]}$

The World Health Organization (WHO)'s End TB Strategy (2015 - 2035) aims to reduce TB deaths by $95 \%$ and incidence by $90 \%$, and to ensure that no household incurs catastrophic healthcare costs due to TB, through three strategic pillars and four principles. ${ }^{[2]}$ In 2018, the United Nations General Assembly convened the first high-level meeting on ending TB, and several countries, including Mozambique, pledged to accelerate and scale up efforts to end the TB pandemic. ${ }^{[3]}$ The third pillar and fourth principle of the End TB Strategy calls for intensified research and innovation as well as adaptation of the programme at country level. One of the means of achieving this is through regular TB programme monitoring and analysis in order to 'optimize implementation and impact and promote innovations. ${ }^{[2]}$

Mozambique is one of 30 high TB burden countries and one of 10 countries with high burdens of the triple TB, TB/HIV and drugresistant TB epidemic. In 2019, the incidence of TB in Mozambique was 361 per 100000 population. ${ }^{[1]}$ The prevalence of HIV in adults was $11.5 \%$, and this disease remains one of the main risk factors for developing TB. ${ }^{[4]}$ Effective $\mathrm{TB}$ control programmes require TB treatment outcomes to be monitored and analysed. In turn, identifying and targeting risk factors for unfavourable outcomes is vital for improving treatment success rates. ${ }^{[2,5]}$

\section{Objectives}

To describe the clinical characteristics of TB in children and adults in Bilene District in Gaza Province, Mozambique, over 43 months and to assess determinants of unfavourable treatment outcomes. 


\section{Methods}

\section{Study design and setting}

This retrospective cohort study took place in Bilene District (located in southern Gaza, population 155526 in 2016), on the southern coast of Mozambique. Bilene District extends across $3200 \mathrm{~km}^{2}$ and had a population of 57319 in 2016; the capital is the town of Macia. ${ }^{[6]}$ The district has 11 health units, including the reference health centre for the district (Centro de Saúde de Macia) and 10 peripheral health centres. In the past, the reference centre was solely responsible for TB notifications in the district, but with the expansion of TB services in recent years the district now has $4 \mathrm{~TB}$-notifying health facilities (the other 5 still report cases through the Macia health centre).

In Gaza, notified new TB cases increased from 6309 in 2015 (445 per 100000 population) to 8302 in 2019 (546 per 100000 ). In 2019, only $22 \%$ of new cases were bacteriologically confirmed. For drugsensitive $\mathrm{TB}$, the treatment success rate was $92 \%$, the death rate $5 \%$, and the loss to follow-up rate $1 \%$. For multidrug-resistant (MDR) $\mathrm{TB}$, these figures were $51 \%, 27 \%$ and $13 \%$, respectively (Balanço das actividades do Programa da Tuberculose - Anual 2018/2019, Província de Gaza - annual reports of the province, unpublished and archived at the provincial authorities).

\section{Patients and study period}

The study population was patients registered in the Macia health centre TB unit from 1 January 2016 to 31 July 2019. We included all registered patients (children and adults) diagnosed and treated for drug-sensitive TB. Exclusion criteria were diagnosis of and treatment for MDR TB, and missing data for the final treatment outcome.

\section{Study variables}

The study included the following variables: age, sex, place of residence, location of disease, type of patient (new TB case or relapse), HIV serology, antiretroviral treatment (ART), household contacts screened for TB, microbiological results and final treatment outcome. Variables were defined according to the Mozambique National Tuberculosis Programme (NTP) guidelines, based on standard WHO definitions. ${ }^{[7-9]}$

Location of disease. Patients were classified as having: (i) pulmonary $\mathrm{TB}$, affecting the lungs (the most frequently encountered form); or (ii) extrapulmonary $\mathrm{TB}$, affecting organs outside the lung (e.g. meninges, bones, intestines).

Bacteriology. Bacteriological diagnosis of TB is done using the GeneXpert test and then smear microscopy (identification of Koch's bacillus) and culture on sputum or other biological fluids. Bacteriological results are presented as follows: (i) GeneXpert Mycobacterium tuberculosis (MTB) detected - in the case of a positive molecular TB test, the patient should start TB treatment according to the resistance profile found (rifampicin-resistant MTB or not); the laboratory algorithm states that when GeneXpert is positive, it should be followed by a smear microscopy test for further laboratory follow-up of treatment; (ii) GeneXpert MTB not detected - patients with a negative molecular test for TB can still have a clinical diagnosis (based on symptoms and signs of TB); (iii) smear positive - on microscopic testing, one or more Koch's bacilli are identified in the smear; (iv) smear negative - on microscopic testing, no Koch's bacilli are found, but patients may still have a clinical diagnosis; and $(v)$ culture positive - there is colony growth of Koch's bacillus (active TB disease).

Clinical cases. These are classified as: (i) pulmonary TB, GeneXpert MTB detected or not detected, smear positive - the patient has active TB disease and should start treatment according to resistance profile; laboratory follow-up will be done with smear microscopy according to guidelines; (ii) pulmonary TB, GeneXpert MTB detected and smear negative - the patient has active TB disease and should start treatment according to the resistance profile; laboratory follow-up will be done with smear microscopy according to guidelines; (iii) pulmonary TB, GeneXpert not detected and smear negative - the patient has been clinically diagnosed with TB and starts treatment; laboratory follow-up is not done, and the patient is followed up clinically; (iv) extrapulmonary TB with biological fluids - the patient can be tested in the laboratory by GeneXpert and smear microscopy and follows the same procedure as for pulmonary TB; and $(v)$ extrapulmonary TB without biological fluids - the patient is clinically diagnosed, starts treatment, and is followed up clinically.

Treatment outcome. Outcomes are defined as: (i) cured - this endpoint is based on the result of the smear microscopy test or culture at the beginning and end of treatment; the patient is cured if they started with a positive smear and completed treatment with a negative smear or a negative culture; (ii) treatment completed - the patient has completed treatment but has no bacteriological results to determine cure at the end of treatment; (iii) treatment failure - the patient remains smear positive or culture positive at the 5th month of treatment, with good treatment adherence; (iv) loss to follow-up a patient who discontinued treatment for $\geq 2$ consecutive months after starting; $(v)$ death - patient died during treatment (from any cause); and ( $v i$ ) transferred - a patient who was transferred to another health facility before the end of treatment and there is no outcome. The classifications of 'cured' and 'treatment completed' are considered TB treatment successes, while unfavourable treatment outcome comprises treatment failure, death and loss to follow-up.

\section{Statistical analysis}

Data processing and analysis were undertaken using Excel 2010 (Microsoft Corp., USA). Patients' epidemiological and clinical characteristics were analysed using descriptive statistics. Continuous and categorical variables are expressed as medians (interquartile range (IQR)). Differences between groups were compared using the Mann-Whitney $U$-test for continuous variables and Pearson's $\chi^{2}$ test for categorical variables; $p$-values $<0.05$ were considered statistically significant. Associations were expressed using odds ratios and $95 \%$ confidence intervals (CIs).

Statistically significant variables identified in the bivariable analysis $(p<0.05)$ were entered one by one into a logistic regression. The adjusted values were expressed as adjusted odds ratios (aORs) with their 95\% CI. The Hosmer-Lemeshow test was used to assess the predictive accuracy (discrimination) of unfavourable TB treatment outcomes. Statistical data analysis was performed using SPSS Statistics for Windows, version 22.0 (IBM Corp., USA).

\section{Ethical considerations}

The study was conducted according to the guidelines of the Declaration of Helsinki and approved by the Gaza Bioethics Committee for Health (ref. no. 19/CIBS-Gaza/2021, protocol code 09/CIBS-Gaza/2020, 25 February 2021). No informed consent was necessary, as the study was a secondary analysis of existing data that are routinely collected as part of standard medical care.

\section{Results}

Clinical and demographic characteristics of TB patients enrolled in the NTP

A total of 3012 TB-infected patients received antituberculosis treatment based on rifampicin, isoniazid, pyrazinamide and 
ethambutol from 1 January 2016 to 31 July 2019. Of these, 358 (11.9\%) were children aged $<14$ years, $2654(88.1 \%)$ were adults, and 1522 (50.5\%) were male. The vast majority ( $n=2581 ; 85.7 \%)$ were new TB cases (Table 1).

Most patients with TB presented with pulmonary manifestations ( $n=2831 ; 94.0 \%$ ). At diagnosis, nearly two-thirds ( $n=1835 ; 60.9 \%)$ were serologically diagnosed with an HIV co-infection, of whom virtually all ( $n=1830 ; 99.7 \%)$ were on ART. A quarter $(n=768 ; 25.5 \%)$ of index TB cases had contact screening, and the median (IQR) number of screening contacts per index TB case was $3(2-5)$. Nearly half $(n=356 ; 46.5 \%)$ of screened contacts initiated TB prophylaxis with isoniazid (Table 1).

\section{Differences in sputum microbiology diagnostics and follow-up between children and adults}

No diagnostic bacteriological test (GeneXpert MTB/Rif or smear microscopy) was done at diagnosis in 1250 patients (41.5\%), with a higher proportion of children not undergoing tests $(n=293 ; 81.8 \%)$ compared with adults $(n=957 ; 36.1 \%)(p<0.001)$. This proportion increased during the months of treatment follow-up in both groups. At the end of TB treatment, the proportion of children and adults who did not have the last smear microscopy test done was similarly high at $99.4 \%(n=356)$ and $97.7 \%(n=2594)$, respectively (Table 1$)$.

\section{Differences in TB outcomes between children and adults} Overall, 2863 patients had successful TB treatment (treatment success rate $95.1 \%)$. The success rate in children (98.0\%) was better than in adults $(94.6 \%)(p=0.005)$. Ninety-seven patients died (3.2\%). Although the overall death rate was low in both groups, it was lower in children (1.4\%) compared with adults $(3.5 \%)(p=0.035)$ (Table 1$)$.

\section{Predictors of unfavourable outcomes of TB treatment in children}

Of 358 children analysed, only 7 (2.0\%) had unfavourable outcomes. Age, sex, location of disease, TB diagnosis, HIV status and microbiological study performed at diagnosis were not associated with unfavourable outcomes (Table 2).

\section{Predictors of unfavourable outcomes of TB treatment in adults}

Of the 2654 adults studied, 142 (5.4\%) had an unfavourable outcome. Multivariable logistic regression analysis showed that factors independently associated with an unfavourable TB treatment outcome were male sex (aOR 1.48; 95\% CI $1.04-2.12$; $p=0.029$ ), recurrent $\mathrm{TB}$ infection (aOR 1.63; 95\% CI $1.05-2.50 ; p=0.027$ ), TB/HIV co-infection (aOR 2.17; 95\% CI $1.43-3.29$; $p<0.001$ ), and positive microbiological sputum results (aOR 5.27; 95\% CI 3.25 $8.54 ; p<0.001$ ) (Table 3 ). In this model, the $p$-value for the HosmerLemeshow test of goodness of fit was 0.46 , with an area under the receiver operating curve of 0.717 ( $95 \%$ CI $0.677-0.757)$. The anatomical site of the infection was not significantly associated with TB treatment outcome.

\section{Discussion}

The results of the present study are not very different from those of a previous study in southern Mozambique, which found that male sex, recurrent TB, HIV co-infection and a negative TB smear at diagnosis were predictors of unfavourable treatment outcomes. ${ }^{[10]}$

Our TB patients were predominantly male and typically aged 25 64 years, as seen in studies in other parts of Africa and beyond. ${ }^{[5,11,12]}$ Men may be diagnosed with TB more frequently because of the risk factors and health-seeking behaviour of this group: many men in Gaza are migrant workers (mainly miners) in South Africa (SA), who tend to return home when ill for treatment and home care by their family. ${ }^{[11]}$ Migrant workers' age usually falls within the age range most observed in our study. This finding raises concerns about the impact of TB on the country's economy, so future research in this field is needed to inform policy. ${ }^{[13]}$

The TB/HIV co-infection prevalence $(60.9 \%)$ in this study was much higher than the 2019 national average (34\%). This finding can be attributed to the fact that Gaza is the province with the highest HIV prevalence in Mozambique (24.4\% in people aged 15 - 49 years, the age group most affected by TB). ${ }^{[14]}$ Gaza is one of the provinces with the highest TB case notifications in the country, and its location along the border with SA means that it has a large community of workers who migrate south to work in the mines. ${ }^{[13]}$ The Macia health centre is the reference health facility for the district for complicated cases and TB notifications, and this may result in an overestimation of TB/HIV prevalence. ${ }^{[15]}$

Study findings on TB/HIV co-infection align with similar studies in Mozambique and elsewhere on the continent. ${ }^{[16-19]}$ Reasons for this may include the interaction between the two diseases in worsening each other's progress, suboptimal HIV management during the TB episode (low CD4 T-cell counts, high viral load, and increased risk of opportunistic infections), and increased drug burden to the co-infected patient. ${ }^{[16-19]}$ The high TB/HIV prevalence and increased risk of poor TB treatment outcomes in this population highlight the importance of $\mathrm{TB}$ screening and preventive treatment in patients living with HIV ${ }^{[1]}$

The treatment success rate in the study was well above the End TB Strategy target and in line with the $93 \%$ rate reported for 2018 by the NTP as well as in other similar local studies. ${ }^{[1,11]}$ This is a result of the significant progress Mozambique has made in its NTP, which has expanded access to community TB services, successfully implemented and scaled up the One Stop TB/HIV model, established community-based directly observed therapy, and improved the data quality in TB registers and patient charts, among other measures. These investments have doubtless played a role in improving treatment adherence. ${ }^{[20]}$

In our cohort, as in others in Ghana, Zambia and Ethiopia, recurrent TB infections were presumed to be due to poor treatment adherence and a higher risk of having drug-resistant TB (which may have been initially missed or not diagnosed). ${ }^{[12,16]}$

A systematic review by Chaves Torres et al. ${ }^{[17]}$ reported that a negative sputum smear at 2 months' follow-up was a predictor of treatment success, but noted that there was still a lack of evidence for the predictive value of a positive smear at 2 months. Our study evaluated the microbiological test results at diagnosis and found that patients who were diagnosed with positive microbiology were at increased risk of poor treatment outcomes. These patients may have a higher bacillary load and a greater likelihood of having cavitary TB, worsening their prognosis. ${ }^{[21,22]}$

\section{Study strengths and limitations}

The strength of this study lies in its large sample size, the length of the study period, the use of a comprehensive national TB register, and inclusion of patients from the reference health facility as well as several satellites. However, the study also had some limitations. Only patients with drug-sensitive TB included in the TB register were evaluated, and data collection was limited to the information available in the TB register and on the TB patient card. As it was a retrospective study, data were incomplete on certain aspects (e.g. laboratory data, 


\section{Table 1. Clinical characteristics of patients with TB and enrolled in the National Tuberculosis Programme}

\begin{tabular}{|c|c|c|c|c|}
\hline & Total $(N=3012)$ & Children $(N=358)$ & Adults $(N=2654)$ & $p$-value \\
\hline \multicolumn{5}{|l|}{ Age (years), $n(\%)$} \\
\hline$\leq 14$ & $358(11.9)$ & - & - & \\
\hline $15-24$ & $236(7.8)$ & - & - & \\
\hline $25-64$ & $2107(70.0)$ & - & - & \\
\hline$\geq 65$ & $311(10.3)$ & - & - & \\
\hline \multicolumn{4}{|l|}{ Sex, $n(\%)$} & 0.92 \\
\hline Female & $1490(49.5)$ & $178(49.7)$ & $1312(49.4)$ & \\
\hline Male & $1522(50.5)$ & $180(50.3)$ & $1342(50.6)$ & \\
\hline \multicolumn{4}{|l|}{ Location of disease, $n(\%)$} & 0.73 \\
\hline Extrapulmonary & $181(6.0)$ & $23(6.4)$ & $158(6.0)$ & \\
\hline Pulmonary & $2831(94.0)$ & $335(93.4)$ & $2496(94.0)$ & \\
\hline \multicolumn{4}{|l|}{ TB diagnosis, $n(\%)$} & $<0.001^{*}$ \\
\hline New diagnosis & $2581(85.7)$ & $327(91.3)$ & 2254 (84.9) & \\
\hline All other ${ }^{\dagger}$ & $431(14.3)$ & $31(8.7)$ & $400(15.1)$ & \\
\hline \multicolumn{4}{|l|}{ HIV status, $n(\%)$} & 0.24 \\
\hline Negative & $1177(39.1)$ & $150(41.9)$ & $1027(38.7)$ & \\
\hline Positive & $1835(60.9)$ & $208(58.1)$ & $1627(61.3)$ & \\
\hline \multicolumn{4}{|l|}{ ART $(n=1835), n(\%)$} & 1.00 \\
\hline Yes & $1830(99.7)$ & $208(100)$ & $1622(99.7)$ & \\
\hline No & $5(0.3)$ & 0 & $5(0.3)$ & \\
\hline \multicolumn{4}{|l|}{ Screening contact } & $0.013^{*}$ \\
\hline No, $n(\%)$ & $2244(74.5)$ & $168(80.8)$ & $1183(72.7)$ & \\
\hline Yes, $n(\%)$ & $768(25.5)$ & $40(19.2)$ & $444(27.3)$ & \\
\hline Screenings per patient, median (IQR) $(n=768)$ & $3(2-5)$ & $3(2-5)$ & $4(2-6)$ & 0.18 \\
\hline \multicolumn{4}{|l|}{ Contacts who started TB prophylaxis $(n=768)$} & 0.65 \\
\hline No, $n(\%)$ & $410(53.4)$ & $36(56.3)$ & $374(53.3)$ & \\
\hline Yes, $n(\%)$ & $356(46.5)$ & $28(43.8)$ & $328(46.7)$ & \\
\hline Contacts/index case who started prophylaxis $(n)$, median (IQR) & $1(1-2)$ & $1(1-2)$ & $1(1-2)$ & 0.92 \\
\hline \multicolumn{4}{|l|}{ Microbiological study at diagnosis, $n(\%)$} & $<0.001^{\star}$ \\
\hline Negative & $1452(48.2)$ & $62(17.3)$ & $1390(52.4)$ & \\
\hline Positive & $310(10.3)$ & $3(0.8)$ & $307(11.6)$ & \\
\hline Not done & $1250(41.5)$ & $293(81.8)$ & $957(36.1)$ & \\
\hline \multicolumn{4}{|l|}{ Microbiological study at 2 months, $n(\%)$} & $<0.001^{*}$ \\
\hline Negative & $302(10.0)$ & $4(1.1)$ & $298(11.2)$ & \\
\hline Positive & $17(0.6)$ & 0 & $17(0.6)$ & \\
\hline Not done & $2693(89.4)$ & $354(98.9)$ & $2339(88.1)$ & \\
\hline \multicolumn{4}{|l|}{ Microbiological study at 5 months, $n(\%)$} & $<0.001^{*}$ \\
\hline Negative & $276(9.2)$ & $3(0.8)$ & $273(10.3)$ & \\
\hline Positive & $5(0.2)$ & $0(0)$ & $5(0.2)$ & \\
\hline Not done & $2731(90.7)$ & $355(99.2)$ & $2374(89.5)$ & \\
\hline \multicolumn{4}{|l|}{ Microbiological study at end of treatment, $n(\%)$} & $0.033^{*}$ \\
\hline Negative & $62(2.1)$ & $2(9.6)$ & $60(2.3)$ & \\
\hline Positive & 0 & 0 & 0 & \\
\hline Not done & $2950(97.9)$ & $356(99.4)$ & $2594(97.7)$ & \\
\hline \multicolumn{5}{|l|}{ Outcome, $n(\%)$} \\
\hline Treatment completed & $2599(86.3)$ & $348(97.8)$ & $2251(84.8)$ & $<0.001^{*}$ \\
\hline Cured & $264(8.8)$ & $3(0.8)$ & $261(9.8)$ & $<0.001^{*}$ \\
\hline Treatment failure & $13(4.4)$ & $1(0.3)$ & $12(0.5)$ & 1.00 \\
\hline Death & $97(3.2)$ & $5(1.4)$ & $92(3.5)$ & $0.035^{*}$ \\
\hline Loss to follow-up & $36(1.2)$ & 0 & $36(1.4)$ & $0.027^{*}$ \\
\hline TB treatment successes ${ }^{\ddagger}$ & $2863(95.1)$ & $351(98.0)$ & $2512(94.6)$ & $0.005^{\star}$ \\
\hline \multicolumn{5}{|c|}{$\begin{array}{l}\mathrm{TB}=\text { tuberculosis; } \mathrm{ART}=\text { antiretroviral treatment; } \mathrm{IQR}=\text { interquartile range. } \\
{ }^{*} \mathrm{Statitstically} \text { significant }(p<0.05) \text {. } \\
\text { 'Of } 431 \text { patients, } 31 \text { children and } 395 \text { adults were relapses; } 5 \text { adults were re-initiated on treatment after loss to follow-up. } \\
\text { 'TB treatment was considered successful if outcome was 'cured' or 'treatment completed. }\end{array}$} \\
\hline
\end{tabular}




\section{Table 2. Predictors of TB treatment outcome in children}

\begin{tabular}{|c|c|c|c|c|}
\hline & Successful $(N=351)$ & Unfavourable $(N=7)$ & Crude OR $(95 \%$ CI $)$ & $p$-value \\
\hline Age (years), median (IQR) & $10(8-13)$ & $6(2-10)$ & $0.93(0.77-1.12)$ & 0.42 \\
\hline \multicolumn{5}{|l|}{ Sex, $n(\%)$} \\
\hline Female & $175(49.9)$ & $3(42.9)$ & 1 & \\
\hline Male & $176(50.1)$ & $4(57.1)$ & $1.00(0.97-1.03)$ & 1.00 \\
\hline \multicolumn{5}{|l|}{ Location of disease, $n(\%)$} \\
\hline Extrapulmonary & $22(6.3)$ & $1(14.9)$ & 1 & \\
\hline Pulmonary & $329(93.7)$ & $6(85.7)$ & $0.97(0.89-1.06)$ & \\
\hline TB diagnosis, $n(\%)$ & & & & 0.47 \\
\hline New diagnosis & $321(85.7)$ & $6(85.7)$ & 1 & \\
\hline All other & $30(8.5)$ & $1(14.3)$ & $1.01(0.95-1.09)$ & \\
\hline HIV status, $n(\%)$ & & & & 0.46 \\
\hline Negative & $146(41.6)$ & $4(57.1)$ & 1 & \\
\hline Positive & $205(58.4)$ & $3(42.9)$ & $0.98(0.95-1.01)$ & \\
\hline \multicolumn{5}{|c|}{ Microbiological study at diagnosis, $n(\%)$} \\
\hline Negative & $61(17.4)$ & $1(14.3)$ & 1 & - \\
\hline Positive & $3(0.9)$ & 0 & NA & 1.00 \\
\hline Not done & $287(81.8)$ & $6(85.7)$ & $1.27(0.15-10.78)$ & 0.82 \\
\hline
\end{tabular}

Table 3. Predictors of successful (cured, treatment completed) and unfavourable (treatment failure, death, and loss to follow-up) TB treatment outcomes in adults

\begin{tabular}{|c|c|c|c|c|c|c|}
\hline & $\begin{array}{l}\text { Successful } \\
(N=2512)\end{array}$ & $\begin{array}{l}\text { Unfavourable } \\
(N=142)\end{array}$ & Crude OR (95\% CI) & $p$-value & aOR $(95 \% \mathrm{CI})$ & $p$-value \\
\hline Age (years), median (IQR) & $40(31-55)$ & $37.5(30-48)$ & $0.98(0.97-0.99)$ & $0.009^{*}$ & $0.99(0.98-1.00)$ & 0.18 \\
\hline \multicolumn{7}{|l|}{ Age group (years), $n(\%)$} \\
\hline $15-24$ & $219(8.7)$ & $17(12.0)$ & 1 & & $\mathrm{NC}$ & - \\
\hline $25-34$ & $621(24.7)$ & $41(28.9)$ & $0.85(0.47-1.52)$ & 0.59 & $\mathrm{NC}$ & - \\
\hline $35-44$ & $635(25.3)$ & $40(28.2)$ & $0.81(0.45-1.46)$ & 0.49 & $\mathrm{NC}$ & - \\
\hline $45-54$ & $377(15.0)$ & $19(13.4)$ & $0.64(0.33-1.27)$ & 0.21 & $\mathrm{NC}$ & - \\
\hline $55-64$ & $357(14.2)$ & $17(12.0)$ & $0.61(0.30-1.27)$ & 0.16 & $\mathrm{NC}$ & - \\
\hline$\geq 65$ & $303(12.1)$ & $8(5.8)$ & $0.34(0.14-0.80)$ & $0.014^{*}$ & $\mathrm{NC}$ & - \\
\hline Sex, $n(\%)$ & & & & $0.003^{*}$ & & \\
\hline Female & $1249(50.1)$ & $53(37.3)$ & 1 & & 1 & \\
\hline Male & $1253(49.9)$ & $89(62.7)$ & $1.68(1.19-2.39)$ & & $1.48(1.04-2.12)$ & $0.029^{*}$ \\
\hline Location of disease, $n(\%)$ & & & & 0.87 & & 0.35 \\
\hline Extrapulmonary & $150(6.0)$ & $9(5.6)$ & 1 & & 1 & \\
\hline Pulmonary & $2362(94.0)$ & $134(94.4)$ & $1.06(0.51-2.21)$ & & $1.47(0.68-3.15)$ & \\
\hline TB diagnosis, $n(\%)$ & & & & $0.038^{\star}$ & & \\
\hline New diagnosis & $2142(85.3)$ & $112(78.9)$ & 1 & & 1 & \\
\hline All other & $370(14.7)$ & $30(21.1)$ & $1.55(1.02-2.35)$ & & $1.63(1.05-2.50)$ & $0.027^{\star}$ \\
\hline HIV status, $n(\%)$ & & & & $<0.001^{*}$ & & $<0.001$ \\
\hline Negative & $995(39.6)$ & $32(22.5)$ & 1 & & 1 & \\
\hline Positive & $1517(60.4)$ & $110(77.5)$ & $2.25(1.59-3.36)$ & & $2.17(1.43-3.29)$ & \\
\hline \multicolumn{7}{|c|}{ Microbiological study at diagnosis, $n(\%)$} \\
\hline Negative & $1354(53.9)$ & $36(25.4)$ & 1 & - & 1 & - \\
\hline Positive & $268(10.7)$ & $39(27.5)$ & $5.47(3.47-8.71)$ & $<0.001^{*}$ & $5.27(3.25-8.54)$ & $<0.001^{\star}$ \\
\hline Not done & $890(35.4)$ & $67(47.2)$ & $2.83(1.87-4.28)$ & $<0.001^{*}$ & $2.90(1.89-4.43)$ & $<0.001^{\star}$ \\
\hline
\end{tabular}


comorbidities, opportunistic infections and treatment adherence) that could have affected treatment outcomes. The study team was unable to discriminate between sputum smear and GeneXpert results from the TB register and TB patient chart; additionally, 1 in 10 patients ( $81.8 \%$ of whom were children) did not undergo a diagnostic microbiological test. As the data were de-identified (part of the retrospective design), the study team was unable to follow up on TB/HIV co-infected patients in the HIV database. The study could not evaluate nutritional factors, although previous studies have indicated an association between TB and nutritional status that may affect treatment outcomes. ${ }^{[12,23]}$ Future studies should look to integrate findings from the TB register and HIV database for TB/HIV co-infected patients and collect socioeconomic and nutritional status for a complete evaluation of prognostic factors.

\section{Conclusions}

More than half our patients had a bacteriological test done (GeneXpert MTB/Rif or smear microscopy) at diagnosis. Characteristics independently associated with an unfavourable TB treatment outcome in adults were male sex, recurrent TB infection, positive microbiology, and co-infection with TB and HIV.

There is an urgent need to ensure that all patients have microbiological confirmation, so as to improve the health outcomes of those with positive microbiology. Likewise, scaling up TB preventive therapy in people living with HIV is important, as co-infected patients experience worse treatment outcomes. It remains crucial to improve data quality and adherence to TB screening and diagnostic algorithms. This will improve the quality of care and evidence to better inform future strategies.

\section{Declaration. None.}

Acknowledgements. The authors thank all the staff of the Macia Health Centre, Gaza, Mozambique. We thank Dr Danilo Uandela and Nurse Josefa Chilaluque for their excellent technical assistance, and Meggan Harris for her help in editing the manuscript.

Author contributions. Conceptualisation: DO, IM and A-VN. Data curation: DP, IM, EN and A-VN. Formal analysis: EN and J-MR-R. Investigation: DO and IM. Methodology: DO, IM, EN and A-VN. Supervision: J-MR-R. Writing - original draft: DO, IM and EN. Writing - review and editing: DO, IM, EN, A-VN and J-MR-R. Validation: DO, IM, EN, A-VN and J-MR-R. All authors reviewed the manuscript and approved the final version for submission.

Funding. This research was partially supported by the Tinpswalo Association - Vincentian Association to Fight AIDS and TB.

\section{Conflicts of interest. None.}

Disclaimer. The views and opinions expressed in this article are those of the authors and do not necessarily reflect the official policy or position of any agency to which they are affiliated.
1. World Health Organization. Global Tuberculosis Report 2020. 2020. https://apps.who.int/iris/ bitstream/handle/10665/336069/9789240013131-eng.pdf (accessed 29 August 2021).

2. World Health Organization. The End TB Strategy. 2015. https://www.who.int/teams/globaltuberculosis-programme/the-end-tb-strategy (accessed 17 August 2021).

3. World Health Organization. UN General Assembly High-Level Meeting on ending TB. New York, 26 September 2018. https://www.who.int/news-room/events/un-general-assembly-high-levelmeeting-on-ending-tb (accessed 17 August 2021).

4. Joint United Nations Programme on HIV/AIDS (UNAIDS). Country factsheets: Mozambique. 2020. https://www.unaids.org/en/regionscountries/countries/mozambique (accessed 25 February 2021). 5olden IK, Lillebaek T, Seersholm N, Andersen PH, Wejse C, Johansen IS. Predictors for pulmonary tuberculosis treatment outcome in Denmark 2009 - 2014. Sci Rep 2019;9:12995. https://doi. org/10.1038/s41598-019-49439-9

6. Instituto Nacional de Estatística, Moçambique. Anuário Estatístico 2016. http://www.ine.gov.mz/ estatisticas/publicacoes/anuario/nacionais/anuario-estatistico-2016/view (accessed 29 August
(n) estatisticas/publicacoes/anuario/nacionais/anuario-estatistico-2016/view (accessed 29 August 2021)

7. Programa Nacional de Controlo da Tuberculose, Moçambique. Manual do Manejo Clinico e Programático da Tuberculose Multiresistente. 2019. https://www.misau.gov.mz/index.php/ manuais-directrizes-e-guioes-tb?download=1087: manual-de-manejo-clinico-e-programatico-datuberculose-multiresistente (accessed 11 January 2022).

8. Ministério da Saúde (MISAU)/Programa Nacional de Controlo de Tuberculose (PNCT). Avaliação e manejo de pacientes com Tuberculose, Protocolos Nacionais, 2019. 2nd ed. Maputo: MISAU, 2019. https://www.misau. gov.mz/index.php/manuais-directrizes-e-guioes-tb?download=261:avaliacao-e-

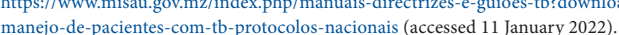

9. World Health Organization. Implementing the WHO Stop TB Strategy: A handbook for national . World Health Organization. Implementing the WHO Stop TB Strategy: A handbook for national
tuberculosis control programmes. 2008. https://apps.who.int/iris/handle/10665/43792 (accessed 29 August 2021)

10. García-Basteiro AL, Respeito D, Augusto OJ, et al. Poor tuberculosis treatment out-comes in Southern Mozambique (2011 - 2012). BMC Infect Dis 2016;16(1):214. https://doi.org/10.1186/ s12879-016-1534-y

11. Nacarapa E, Muchiri E, Moon TD, et al. Effect of Xpert MTB/RIF testing introduction and favorable outcome predictors for tuberculosis treatment among HIV infected adults in rural southern Mozambique: A retrospective cohort study. PLoS ONE 2020:15(3):e0229995. https://doi. org/10.1371/journal pone. 0229995

12. Tola A, Minshore KM, Ayele Y, Mekuria AN. Tuberculosis treatment outcomes and associated factors among TB patients attending public hospitals in Harar Town, Eastern Ethiopia: A five-year retrospective study. Tuberc Res Treat 2019;2019:1503219. https://doi.org/10.1155/2019/1503219

13. Baltazar CS, DeLima YV, Ricardo H, et al. HIV prevalence and TB in migrant miners communities of origin in Gaza Province, Mozambique: The need for increasing awareness and knowledge. PLoS ONE 2020;15(4):e0231303. https://doi.org/10.1371/journal.pone.0231303

14. Ministério da Saúde (MISAU), Instituto Nacional de Estatística (INE), Com a Assistência Técnica de ICF, Moçambique. Inquérito de Indicadores de Imunização, Malária e HIV/SIDA em Moçambique (IMASIDA), 2015. February 2018. https://dhsprogram.com/publications/publication-ais12-aisfinal-reports.cfm (accessed 25 February 2021).

15. Impacto. Projecto de Avaliação Ambiental Estratégica da Zona Costeira - Moçambique, Impacto Projectos e Estudos Ambientais, 2012. https://biofund.org.mz/wp-content/ uploads/2019/01/1547459411-Perfil_Bilene.pdf (accessed 23 August 2021).

16. Nanzaluka FH, Chibuye S, Kasapo CC, et al. Factors associated with unfavourable tuberculosis treatment outcomes in Lusaka, Zambia, 2015: A secondary analysis of routine surveillance data. Pan Afr Med J 2019;32:159. https://doi.org/10.11604/pamj.2019.32.159.18472

17. Chaves Torres NM, Quijano Rodríguez JJ, Porras Andrade PS, Arriaga MB, Netto EM. Factors predictive of the success of tuberculosis treatment: A systematic review with meta-analysis. PLoS ONE 2019;14(12):e0226507. https://doi.org/10.1371/journal.pone.0226507

18. Lisboa M, Fronteira I, Mason PH, Martins MdoRO. National TB program shortages as potential factor for poor-quality TB care cascade: Healthcare workers' perspective from Beira, Mozambique. PLoS ONE 2020;15(2):e228927. https://doi.org/10.1371/journal.pone.0228927

19. Weyer K, Carai S, Nunn P. Viewpoint TB diagnostics: What does the world really need? J Infect Dis 2011;204(Suppl 4):S1196-S1202. https://doi.org/10.1093/infdis/jir452

20. Direç̧ão Nacional de Saúde Publica/Programa Nacional de Controlo da Tuberculose, Moçambique. Plano Estratégico e Operacional 2014 - 2018. Ministério da Saúde, 2014. https://www.misau.gov.mz/ index.php/planos-estrategicos-da-tb (accessed 29 August 2021).

21. Urbanowski ME, Ordonez AA, Ruiz-Bedoya CA, Jain SK, Bishai WR. Cavitary tuberculosis: The gateway of disease transmission. Lancet Infect Dis 2020;20(6):el17-e128. https://doi.org/10.1016/ s1473-3099(20)30148-1

22. Huang Q, Yin Y, Kuai S, et al. The value of initial cavitation to predict re-treatment with pulmonary tuberculosis. Eur J Med Res 2016;21:20. https://doi.org/10.1186/s40001-016-0214-0

23. Osório D-V, Munyangaju I, Muhiwa A, Nacarapa E, Nhangave A-V, Ramos I-M. Lipoarabinomannan antigen assay (TB-LAM) for diagnosing pulmonary tuberculosis in children with severe acute malnutrition in Mozambique. J Trop Pediatr 2021;67(3):fmaa072. https://doi.org/10.1093/tropej/ fmaa072

Accepted 17 December 2021 